RUNNING HEAD: Entrepreneurial Orientation and Philanthropy

Please note, this is a pre-print version of the final manuscript, which may differ slightly from the published version. Please cite as: Mickiewicz, T., Sauka, A. \& Stephan, U. (2014). On the Compatibility of Benevolence and Self-Interest: Philanthropy and Entrepreneurial Orientation. International Small Business Journal. DOI: 10.1177/0266242614555245

\title{
On the Compatibility of Benevolence and Self-Interest: Philanthropy and Entrepreneurial Orientation
}

\author{
Tomasz Mickiewicz * \\ University of Aston \\ Aston Business School \\ and ESRC Enterprise Research Centre \\ Aston Triangle \\ Birmingham \\ B4 7ET, UK \\ tel. 00-44-121 2043038 \\ fax 00-44-20-121 2043306 \\ e-mail: t.mickiewicz@aston.ac.uk \\ Arnis Sauka \\ Stockholm School of Economics in Riga, \\ Strelnieku iela $4 a$ \\ Riga \\ LV 1010, Latvia \\ tel.: 00-371 26043567 \\ e-mail: arnis.sauka@,sseriga.edu \\ Ute Stephan $^{\mathrm{t}}$ \\ University of Aston \\ Aston Business School \\ Aston Triangle \\ Birmingham \\ B4 7ET, UK \\ tel. 00-44-121 2043183 \\ fax 00-44-20-121 2043306 \\ e-mail : $\underline{\text { U.Stephan@aston.ac.uk }}$
}

*All authors contributed equally to this manuscript and are listed in alphabetical order.

${ }^{\mathrm{t}}$ Corresponding author for this submission.

\section{Acknowledgements}

We are grateful to anonymous referees and participants of the Babson College BCERC and the Academy of Management (Entrepreneurship Division) conferences for helpful comments. We also acknowledge financial support by the European Commission: AIGIS project, Grant Agreement no. 225134 as well as SELUSI project FP7-SSH-2007-1, Grant Agreement no. 217622. 


\title{
On the Compatibility of Benevolence and Self-Interest: Philanthropy and Entrepreneurial Orientation
}

\author{
Abstract (157) \\ This study contributes to emerging research on entrepreneurial philanthropy. It explores the \\ philanthropy of owner-managers of small and medium-sized enterprises (SMEs) and \\ investigates whether and why more entrepreneurially oriented (EO) SMEs are also more \\ likely to be philanthropic. We find support for a positive link between EO and philanthropy in \\ a representative sample of 270 Lithuanian SMEs controlling for alternative explanations. We \\ highlight that philanthropy is relatively common amongst SME owner-managers, and thus \\ complement existing research, which views philanthropy as sequentially following wealth \\ generation. In line with our theorizing, further qualitative findings point to drivers of \\ philanthropy beyond those considered in the dominant strategic-instrumental perspective. \\ Building on social psychological theories of motivation, we argue and find that philanthropy \\ can also be an expression of owner-managers altruistic values, and that these values can be \\ compatible and even mutually-reinforcing with entrepreneurship. Our study is set in a \\ transition economy, Lithuania, facilitating the analysis of heterogeneity in attitudes towards \\ philanthropy.
}

\section{Keywords:}

philanthropy, entrepreneurial orientation, transition, values, motivation 


\section{Introduction}

Entrepreneurial philanthropy, broadly understood, refers to charitable giving by commercial entrepreneurs benefitting others outside their businesses. ${ }^{1}$ Entrepreneurial philanthropy has a long history, especially in the USA and the UK, and leading entrepreneurs engaged in philanthropy, such as Bill Gates or Richard Branson are regularly covered in popular media. Yet to date, entrepreneurs' philanthropy has garnered only scarce academic attention (e.g., Shaw et al., 2013): as a phenomenon, entrepreneurs' philanthropy is poorly theorized and researched. This is despite the fact that philanthropy by commercial entrepreneurs is an intriguing phenomenon as it challenges some of the classic assumptions about entrepreneurs as pursuing narrowly defined rational self-interest and personal utility (e.g., Parker, 2009 for an overview). Thus a better understanding of entrepreneurs' philanthropy can also yield important general insights for entrepreneurial motivation.

The few existing studies focus on philanthropic giving by particularly wealthy entrepreneurs, predominantly in the USA and the UK (e.g., Acs and Dana, 2001; Acs and Desai, 2007; Shaw et al., 2013). In particular, Shaw et al. (2013) use Bourdieu's capital theory and analyze 100 high net-worth entrepreneurial philanthropists in the UK. The authors suggest that entrepreneurs' engagement in philanthropy does not come from economic capital (wealth) alone but is facilitated by having other forms of capital (cultural, social and symbolic), which is conducive to entrepreneurs' entry into the field of philanthropy. Their study concludes that the reasons for engaging in philanthropy are complex and multi-facetted, including a desire for legitimacy (using philanthropy as a reputation enhancer), but further investigation is needed. Research by Acs and colleagues (e.g., Acs and Dana, 2001; Acs and Desai, 2007; Acs and Phillips, 2002) similarly focusses on high-net-worth individuals and uses primarily (comparative) case studies to explore the role of entrepreneurs' philanthropy in

\footnotetext{
${ }^{1}$ Our focus is on philanthropy by conventional, commercial entrepreneurs and not on social entrepreneurs. Social entrepreneurs ingrain social-value creating activities directly in their business alongside efforts to create economic value, thus resulting in hybrid organisations (Battilana and Lee, 2014). In contrast commercial entrepreneurs operate predominantly under the economic value creation logic.
} 
the economic system in terms of creating new opportunities for entrepreneurship (e.g. by creating universities).

Thus, extant research highlights that high-net worth individuals face a social obligation of wealth and a norm of "giving back" once success and great wealth are achieved (e.g., Acs and Phillips, 2002). This implies first achieving the self-centered objectives before engaging in other-regarding activities, in a sequential order (Van de Ven et al., 2007). However, the stereotype of "succeeding first and giving back later" has recently been questioned (Grant, 2014: 11). Departing from the 'sequential', we posit that philanthropy may be compatible and simultaneous with entrepreneurship. Consequently our study investigates owner-managers of small and medium-sized enterprises (SMEs) - as opposed to high networth individuals.

Possibly, one of the reasons why philanthropy is seen as sequential, following from wealth and success, is the limited understanding of what motivates entrepreneurs. In the literature to date, the explanation of engagement in philanthropy by businesses is reduced to strategic-instrumental motives. To investigate the link of entrepreneurship and philanthropy, we postulate adopting a more complex theory of human motivation. We complement theorizing on strategic considerations with a social-psychological perspective that especially helps to understand the multi-facetted nature of entrepreneurial motivation.

Strategic management scholars have investigated philanthropic giving by large corporations emphasizing the instrumental value of philanthropy including strategic benefits in terms of enhanced legitimacy and reputation (Wang and Qian, 2011). These concerns may be similar for SMEs, which are typically anchored locally (Evers, 2001). Especially SMEs engaging in high-risk, proactive entrepreneurial strategies and introducing novelty in the market may indeed use philanthropy to gain legitimacy, especially in their local community, to obtain resources and the cooperation of local stakeholders. 
However, such predominantly instrumental accounts of philanthropy have also been challenged. Recent contributions highlight bottom-up drivers of corporate philanthropy originating from a desire to help others (Muller et al., 2014). Similarly, entrepreneurship research increasingly recognizes the multi-facetted motivations underlying owner-managers behavior (Gorgievski et al., 2011; Van der Ven et al., 2007) - in part in response to the emerging social entrepreneurship literature, which highlights that pursuing social goals need not be at odds with acting in an entrepreneurial manner (Mair and Marti, 2006; Estrin et al., 2013). Thus, next to strategic concerns, owner-managers of SMEs may pursue philanthropy out of altruistic, other-regarding motives such as a desire to make a positive difference to the community.

Both the strategic instrumental and the non-strategic altruistic perspective lead to a similar proposition, that there is a positive link between SMEs entrepreneurial orientation (EO) and their engagement in philanthropy. However, distinguishing between these two types of motivation is important, as genuine 'givers' tend to build greater value through their actions than those whose motivation is instrumental (Grant, 2014).

Engagement in philanthropy may also be dependent on the wider context within which SMEs act. Elite entrepreneurs provide role models for philanthropy in such developed economies as the USA and the UK (Acs and Desai, 2007, Shaw et al. 2013), which Acs and colleagues attribute to cultural individualism accompanied by a social norm of the "responsibility of wealth" (Acs and Phillips, 2002). Yet, it is unclear how the entrepreneurship-philanthropy link may look in emerging market economies, particularly in those in transition from command economy (that suppressed individualism and entrepreneurial initiative and undermined social capital including trust and prosocial values), to market economies (based on inclusive economic and political institutions, and characterized by a different set of social norms) (Schwartz and Bardi, 1997; Estrin and Mickiewicz, 2011). By exploring the entrepreneurship-philanthropy link in a transition 
economy (Lithuania), our study sheds light on how generalizable or context-bound the entrepreneurship philanthropy link may be.

To test our theoretical insights, we apply a mixed-method (quantitative and qualitative) design to a representative sample of SME owner-managers to establish to what extent and why philanthropy is compatible with entrepreneurship. In particular, we utilize data derived from a telephone survey with 270 owner-managers of a representative sample of SMEs in Lithuania. We additionally conduct in-depth qualitative follow-up interviews with 10 of these owner-managers. The latter enabled us to deepen our understanding of the instrumental versus other-regarding motivation of entrepreneurs.

Our study advances the understanding of entrepreneurs' philanthropy and extends existing research in three ways. First, we challenge the sequential nature of entrepreneurs' philanthropy and provide evidence that entrepreneurially oriented (EO) firms engage in philanthropy even when they are only moderately successful (yet). We find that rather than resources, entrepreneurial drive is a more important correlate of philanthropy. A corollary is that instead of investigating high net-worth elite entrepreneurs who are the subject of the current literature on entrepreneurial philanthropy, we focus on "typical" entrepreneurs such as SME owner-managers and thus draw attention to an important source of philanthropy that is locally embedded in communities and which has been largely overlooked in the literature to date $^{2}$. Our findings also extend research on entrepreneurial philanthropy to a novel institutional context, were historically support for both entrepreneurship and philanthropy have been weak.

Second, we extend theorizing on the motivations of entrepreneurs, providing insights on the multi-facetted drivers underlying entrepreneurs' philanthropic engagement. To do so we complement the established instrumental-strategic views on philanthropy with a socialpsychological perspective that accentuates intrinsic value-based drivers of philanthropy. The

\footnotetext{
${ }^{2}$ More generally, some have argued that the sociology of entrepreneurship pays too little attention to communities (see Devereaux Jennings et al., 2013).
} 
latter perspective is not considered in the current discourse on philanthropy, but is useful to explain heterogeneity amongst entrepreneurs. Importantly, we highlight that applying a more comprehensive theory of human motivation can help to resolve apparent contractions between individualistic and other-regarding drivers of entrepreneurial action.

Third, our findings also extend research on Entrepreneurial Orientation, which focusses predominantly on economic correlates of EO, by explicating how EO links with positive societal outcomes such as philanthropy.

In the following sections of the paper we first present our theoretical framework and hypotheses, and next the sample, methods and results. Our final conclusions point to both limitations and wider theoretical implications.

\section{Theoretical framework}

\section{Philanthropy}

Our focus is on entrepreneurial philanthropy, i.e. charitable giving by commercial entrepreneurs. Entrepreneurial philanthropy sits between individual, private giving and corporate philanthropy by large firms. Definitions of individual philanthropy refer to "the donation of money to an organization that benefits others beyond one's own family" (Bekkers and Wiepking, 2011, p.925). It is conceived as an "other-regarding", pro-social action intending to contribute to the welfare of others without expecting an immediate return or personal gain (ibid.). By contrast, corporate philanthropy can be defined as 'gifts or monetary contributions given by corporations to social and charitable causes, such as those associated with education, culture, the arts, minorities, health care, and disaster relief' (Wang and Qian, 2011, p. 1161). In large corporations, philanthropy may take forms, which involve careful planning and assessment, such as impact investing (Mair and Hehenberger, 2013) and may evolve into more institutionalized modes of social engagement (business-social partnerships, volunteering, trust funds, e.g. Amato and Amato 2011; Goyal 2006). Especially the recent 
corporate philanthropy literature, including the wider literature on corporate social responsibility, emphasizes economic returns to corporate philanthropy such as better firm financial performance (Lee, 2008; Orlitzky et al. 2003; Wang and Qian, 2011).

As highlighted in the introduction, entrepreneurial philanthropy is different from social enterprise. The latter ingrain social and economic wealth creation in its business model (Battilana \& Lee, 2014), while the former is an activity by an entrepreneur who run first and foremost a commercial enterprise concerned with economic value creation.

\section{Entrepreneurial orientation (EO)}

The economic impact of SMEs varies, which led scholars to focus on dynamic businesses, i.e. especially entrepreneurial SMEs that are characterized by innovativeness, risk taking and proactivity. These dimensions correlate, and are captured in the EO construct. Firms with a strong EO contribute more economically, by higher financial performance, more innovation and market creation (e.g., Rauch et al, 2009; Wales et al, 2013a, 2013b). More specifically, EO is defined as a firm's strategic posture that captures its propensity to act entrepreneurially and to introduce novelty in the market place (e.g., Covin and Slevin 1989; Covin and Wales, 2012; Lumpkin and Dess 1996; Miller 1983; Wales et al., 2013a, 2013b).

First, the EO component of innovation refers to a strategic focus on the development of new products, services and processes. It is in line with classical conceptualizations that see innovation at the core of entrepreneurial activity (e.g., Drucker 1985; Schumpeter 1934). Second, the EO component of risk-taking refers to a firm pursuing opportunities with high but more uncertain chances of return. Thus EO can be seen as a strategic orientation that is 'performance-variance-enhancing' (Wiklund and Shepherd, 2011). Third, pro-activity describes whether a firm is ahead of the market, i.e. it acts anticipating future market trends and competitors' reactions. For the purpose of this research we treat EO as firm-level phenomenon, although for SMEs the owner-manager and the firm often closely overlap (e.g., Welter and Smallbone, 2011). 
EO has become one of the most researched concepts in entrepreneurship with a multitude of studies investigating its impact on firm performance and testing its validity in different contexts (e.g. Baker and Sinkula 2009; Huges and Morgan 2007; Kreiser et al., 2002; Moreno and Casillas, 2008; Short et al., 2009; Wales et al., 2013a). A meta-analysis summarizes over 50 empirical studies drawing on a total sample of over 14,000 firms (Rauch et al., 2009) and finds that firms' EO is significantly and positively related to firm performance. A subsequent systematic review of 158 studies from various disciplines including entrepreneurship, marketing, and ethics, mapped the range of research topics in EO research over the past 30 years (Wales et al., 2013a). The review confirms the focus on firm performance as an outcome of EO, but did not retrieve any studies relating EO to philanthropy (Wales et al., 2013a). Similarly, we are not aware of any studies that would link SMEs' EO with their social orientation more generally.

\section{Entrepreneurial orientation (EO) and philanthropy}

We suggest that two processes likely underlie a potential positive link between EO and philanthropy in SMEs. Firstly, just as larger corporate players, entrepreneurial SMEs may instrumentally adopt philanthropy as having strategic benefits for their business, specifically enhancing their legitimacy. Secondly, intuitive decision-making arguably plays a greater role for SMEs as do the values and motivation of the owner-manager (Welter and Smallbone, 2011), and their engagement in philanthropy may also reflect altruistic value-judgments. We now explain each process in more detail.

Strategic-instrumental considerations to engage in philanthropy. Legitimacy arguments suggest that philanthropy helps entrepreneurially-orientated SMEs to gain acceptance and approval. In particular, entrepreneurially-oriented SMEs may use philanthropy to counterbalance their lack of legitimacy vis-à-vis external stakeholders and gain critical access to resources. Legitimacy refers to "a generalized perception or assumption that the actions of an entity are desirable, proper, or appropriate within some socially constructed 
system of norms, values, beliefs, and definitions.” (Suchman, 1995, p. 574). Firms that are perceived as legitimate find access to resources easier and can rely on greater cooperation with their stakeholders, the wider public, and local government. All of which in turn may allow the firm to run its operations more effectively (Campell 2007; Lee 2008; Luo and Junkunc, 2008; Orlitzky et al. 2003; Wang and Qian 2011).

SMEs characterized by strong EO are particularly visible to the local community and their stakeholders - they "stand out", as they introduce novelty in the market place such as new products, services and processes, thereby potentially disrupting and threating existing practices and competitive equilibria. Similarly, their proactive and risk-embracing orientation emphasizes getting ahead of the competition and first-mover advantages. Such noveltyintroducing firms are often met with skepticism or even perceived as threating by their peers and key stakeholders including the general public and government. Legitimacy is typically conferred when firms abide by the dominant, typical way of doing business, which is precisely what highly entrepreneurially oriented firms do not do. Thus they have a greater need to establish their legitimacy and to convince their stakeholders that their "venture is indeed competent, efficient, effective, worthy, appropriate and/or needed" (Zimmerman and Zeitz, 2002: 416). At the same time, legitimacy is particularly important for entrepreneuriallyoriented SMEs as EO is also a resource-intensive strategy, and legitimacy is crucial in accessing resources. Resource providers including key stakeholders and government are more likely to allow access to resources if they believe that the SME is acting appropriately and competently - i.e. that it will put the resources to "good use", including it is competent enough to generate a return on investment and able to service a line of credit.

More generally, the need for legitimacy may be especially pertinent for SMEs as they are typically closely interlinked with and thus depended on their local community and stakeholders to conduct their business. That is, compared to large corporations, SMEs are more closely socially embedded in their local communities (Evers, 2001; Lang, Fink and 
Kibler, 2014) $)^{3}$. SMEs are less likely to be able and willing to move their production elsewhere. Often their suppliers, financing institutions, customers and co-owners are colocated in their community, and they also need to rely on local government to a greater extent than larger corporations. In short, the local social milieu, or "territorial embeddedness" (Hess, 2004), is important for SMEs (also Lang et al., 2014). By engaging in philanthropy, SMEs can build their legitimacy in the local social milieu, i.e. increase acceptance by their immediate stakeholders, the public, and the local government.

Altruism and value-based considerations to engage in philanthropy. So far we considered instrumental, (narrowly) rational justifications for entrepreneurial firms to engage in philanthropy. However, there is some scant literature that discusses the pro-social motivation of owner-managers of smaller businesses (Pistrui et al., 2000; Gorgievski et al., 2011). In addition, Van der Ven et al. (2007) suggest that altruistic, other-regarding values are not at odds with entrepreneurship. Accordingly, we suggest that entrepreneurs' philanthropy can also be driven by altruistic motivation.

Firstly, entrepreneurs can act upon multiple motivations simultaneously. Thus, entrepreneurs may pursue self-interest aligned with entrepreneurship in parallel to more altruistic motives aligned with philanthropy. Secondly, although altruistic motivation could be cast as being in conflict with self-centered motivation - the two are not necessarily conflicting. The following combinations are also possible: low self-centered motivation combined with low other-regarding motivation (apathy), and strong self-centered motivation accompanied by strong other-regarding motivation ('otherish') (Grant, 2014).

Moreover, Schwartz' - widely validated and replicated - theory of human values maps in more detail the multiple motivations driving behaviors and their patterns of conflict and compatibility (e.g., Schwartz, 1990, 1992, 2009). Schwartz' theory differentiates two aspects

\footnotetext{
${ }^{3}$ The spatial aspect of embeddedness has been emphasized by economic geography. For SMEs local embeddedness in a geographic area, such as a local community, is likely to overlap substantially with their social embeddedness (in networks with other actors). Thus even though the two concepts of embeddedness stress different aspects (Hess, 2004), these are converging for SMEs.
} 
of individualism. Openness to change (contrasted with conservation) drives independent, proactive, novelty, and risk-seeking behaviors, which overlap with EO. By comparison, selfenhancement (contrasted with self-transcendence) is more closely aligned with the core notion of self-interest as elevating oneself over others and seeking material wealth. In Schwartz' (1992) theory, self-enhancement is in conflict with altruistic values, while openness to change is compatible with altruistic values or self-transcendence. Common to both openness to change and altruistic, self-transcendence values is their emphasis on intrinsic motivation, i.e. the attainment of these values is rewarding in itself. By contrast, self-enhancement and conservation values reflect extrinsic motivation; their attainment is rewarding contingent on receiving material rewards and meeting societal expectations (Schwartz, 1992). Thus, the apparent conflict between individualist, entrepreneurial and altruistic motivation, depends on which of the two aspects of individualism dominates (openness to change vs. selfenhancement). This more fine-grained differentiation of individualism allows us to recognize possible compatibilities between entrepreneurship and altruism.

Thirdly, SMEs' altruistic actions seeking to make a positive difference to their local community can also be seen as building social capital (Evers, 2001). Philanthropic giving as an act of goodwill can reinforce norms of generalized reciprocity and thereby foster social capital in the community more generally. It is this 'constructive' aspect that makes us see philanthropy as sharing some characteristics with a more general phenomenon of institutional entrepreneurship, where new institutions are built from below (Estrin et al., 2013). At the same time, charitable giving also builds specific social relationships with those to whom entrepreneurs give.

The distinction between actions that build wider social capital and those that build narrower, specific social networks broadly corresponds to the distinction between the genuine 'givers' and those that adopt giving instrumentally (Grant, 2014). Genuine 'givers' typically receive more positive responses from their environment over longer time (Grant, 2014), and 
philanthropy treated as an intrinsic objective may therefore be a better way of connecting an entrepreneurial SME to the local community and to civic society in particular (e.g., to voluntary community associations). Such connections can over time further strengthen the philanthropy-EO link as they provide access to new knowledge that could further stimulate innovation activities. From this perspective, philanthropy is not only a strategy element compensating for newness; it creates synergy with the core elements of EO via generating access to additional knowledge and opportunities that entrepreneurially oriented firms are in the best position to take advantage of. This is also more generally consistent with research suggesting that EO is conducive to utilizing knowledge-based resources more fully (Wiklund and Shephard, 2003). The critical aspect, however, is that those in the environment are often able to distinguish between instrumental strategies and genuine altruism (Grant, 2014; Van de Ven et al., 2007). While instrumental strategies may be successful in the short run, it is only genuine other-regarding motivated behaviour that secures cooperation of others (and therefore sustained access to key resources) in the long run (Grant, 2014; Van de Ven et al., 2007).

Taken together, we draw on both strategic instrumental and other-regarding valuebased arguments to suggest that philanthropy is positively associated with SMEs' EO. However, the interpretation of the association varies according to which argument dominates. The instrumental-strategy perspective implies a straightforward causal relationship. The altruistic, other-regarding argument implies that the association is determined jointly by compatibilities within the value set of the entrepreneurial owner-managers. We shed some light on the relative importance of strategic-instrumental (self-enhancement) and otherregarding (self-transcending) motivation for philanthropic action based on the qualitative extension of our survey. 


\section{The context: Lithuania}

Similar to other countries in Central Europe, entrepreneurship re-emerged in Lithuania as one of the key drivers of economic recovery in the early 1990s that followed the implosion of the Soviet economic system. New enterprises and SMEs in Lithuania could quickly fill domestic market gaps inherited from the command economy system of supply (Aidis and Mickiewicz, 2006). Yet the environment remained challenging, as the economic transition implied an "uncertain, ambiguous and turbulent institutional framework", which led to a "heterogeneity of entrepreneurial responses to institutional conditions" (Welter and Smallbone, 2011: 107). In such a transition context, entrepreneurial orientation may be seen as a "prospecting" strategy responding with innovation and flexibility to the transition environment (Peng 2000: 178; Welter and Smallbone, 2011: 110).

Moreover, as emphasized by Welter and Smallbone (2011), the reality of heterogeneous responses to a similar (turbulent) institutional context implies that “institutionalist perspectives ... may be criticized for being overly deterministic in circumstances where human agency can also play a role" and more attention should be paid to venture- and person- related factors (Ibid.: 120). Thus the transition environment allows particularly well to examine diversity in SME owner-managers' motivation (strategicinstrumental and other-regarding altruistic) for philanthropy.

The turbulence in the transition environment results from the uneven pace of reforming various aspects of formal institutions, and inconsistences emerging from having reformed formal institutions whilst change in culture and dominant attitudes remains slow (Mickiewicz, 2010). Despite the initial wave of entrepreneurship in Central Europe after the transition started, the Soviet system left a legacy of social attitudes that were not conducive to entrepreneurship and the rates of entrepreneurial entry remained relatively lower compared with other countries at a similar level of development in South East Asia and Latin America (Estrin and Mickiewicz, 2011). Some of those inherited attitudes are not only detrimental to 
entrepreneurship (Ibid.), but also to any private self-organization, including philanthropy (Boettke and Rathbone, 2002).

In particular, the Soviet cultural legacy is described by Sztompka (1996) as 'block culture' that emphasizes dependency over self-reliance, conformity over individualism, and extremism and rigidity in beliefs over tolerance and innovation (see also: Estrin and Mickiewicz, 2011; Schwartz and Bardi 1997). These cultural traits did not necessary follow from the official Soviet ideology that stressed cooperation and pro-social values, but resulted directly from adaptation to the actual political, economic and social conditions (Schwartz and Bardi, 1997). The command economy system was organized in a hierarchical way and discouraged spontaneous action. The prevailing conditions of surveillance and detailed monitoring of citizens destroyed trust and horizontal cooperation (Schwartz and Bardi 1997). Thus most aspects of the value system supporting entrepreneurship such as openness to change values remain weak in transition economies (Schwartz and Bardi, 1997).

Estrin and Mickiewicz (2011) provide evidence that cultural traits change slowly and the shift in values may only come with generational change (also: Inglehart, 2008). Across the countries in the former Soviet block that embarked on the process of institutional transition, it is the youngest generation that represents cultural change, while much of the older generation lives in the past. This observation is important as our respondents represent an age cohort, whose values were formed under the old regime.

More generally, in examining the EO - Philanthropy link in the transition context we stake the odds against our hypothesis. Most research on both entrepreneurship and philanthropy to date is set in the USA or the UK, i.e. in countries which are characterized by entrepreneurial dynamism and by active community life, including philanthropy ${ }^{4}$. To confirm the link between EO and philanthropy in USA or UK context may thus not be surprising. In contrast, we consider an environment, where both entrepreneurial values and values

\footnotetext{
${ }^{4}$ Even if there are some doubts where the long term trends in the USA are leading; see Putnam (1995).
} 
supporting decentralized, pro-social initiatives including philanthropy are weak. Here, it is likely that the strength of the relationship between philanthropy and entrepreneurship would be attenuated. Therefore, if we could find support for our hypothesis in such an environment, we may have more confidence that these links can be generalized across different cultures.

\section{Methods}

\section{Sample}

The study draws on 270 phone interviews with randomly sampled owner-managers of small and medium-sized enterprises (SMEs), i.e. firms with less than 250 employees according to the SME definition adopted by the European Union. Interviews were conducted in Lithuania during January- March, 2008. The firm contact information was obtained from the official statistics compiled by the Lithuanian State Enterprise Centre of Registers.

The sampling frame was 800 randomly selected companies from the official register. Out of the list of 800 firms, 238 companies could not be contacted (either moved to another office and the new tenants could not provide the correct contact information, or the phone line was not in use anymore). Additionally, 42 phone numbers appeared to be non-existent, which can be explained either by the probability that those companies have gone out of business or by errors in the company registry. During the initial contact phase, the company representatives (usually administrators or secretaries) were informed about the study, and were asked for direct contact with the owner or owner-manager.

Out of 520 companies that we established contact with, 162 refused to connect us to the top person(s), which was typically motivated by time constraints, winter holidays or other reasons. Talking directly to the owners/owner-managers of the firm, in 83 cases the respondents declared that they had no willingness to participate in the survey. Finally, 275 owners or owner-managers of SMEs agreed to be interviewed, and the corresponding number of questionnaires was filled in, which gives an overall response rate of $34.4 \%$. Five of those 
275 were excluded from the present analyses due to missing data. On average, interviews lasted 15 minutes. Interviews were focused and length was kept to a minimum to avoid interview fatigue and thus unreliable data.

The final sample represented 270 enterprises from the five largest Lithuanian cities as well as 27 other smaller towns. The enterprises were on average six years old (Mean (M): 5.98, Standard Deviation (SD): 2.02) and had a mean of 18 employees (M: 18.47, SD: 23.68). The enterprises were active in retail trade (10.0\% of sample), wholesale trade $(16.3 \%)$, construction (14.4\%), manufacturing (17.4\%) and other services (41.5\%). We find support for the notion that ours is a representative sample when comparing it against the 4,770 firms with less than 250 employees that are registered in the Orbis database for Lithuania ${ }^{5}$.

In addition, to gain a more detailed understanding of the motivations and considerations of owner-managers' philanthropy, we conducted in-depth follow up interviews with 10 owner-managers from the final sample of 270 enterprises in 2013 . The interviews explored their engagement in philanthropy, the reasons behind this engagement and the benefits created from it. We offer insights from these interviews in the results section to shed light on what might drive the pattern of results observed in the quantitative analysis, and in particular on the difference between strategic-instrumental and altruistic-'other regarding' drivers of philanthropy.

Participation in the survey and interview study was voluntary. Owner-managers were informed about the purpose and content of the interview and that they had the right to withdraw from the interview at any point without needing to specify a reason for doing so. All answers were treated confidential and the dataset is anonymized.

\footnotetext{
${ }^{5}$ This is the only available dataset with a wide coverage of firms, however it is known to oversample large firms. The mean number of employees in the Orbis sample is higher than in our sample, at 61 employees. We find that for our sample the $25^{\text {th }}$ percentile corresponds to 2 full-time permanent employees, whilst the corresponding number is 7 for the Orbis database. The median number of employees in the Orbis database is 20 employees, and closely similar to the median of 18 employees in our sample. A sector comparison reveals that percentages for construction, manufacturing and retail trade are highly similar. There is one exception: Orbis firms are more concentrated in wholesale trade ( $31 \%$ versus $16 \%$ in our sample) which comes at the cost of a correspondingly lower share of other services. Again this seems consistent with size differences as discussed above: many service and repair firms are of micro size, while wholesale trade firms tend to be large.
} 
Philanthropy. Our dependent variable is based on the survey instrument capturing the charitable contributions of SMEs. We asked the following question: "In the past 12 months, has your business contributed to the sponsorship for social needs (donations for hospitals, social organizations, sports, etc.)?” The answers were recorded on a 5-point Likert scale: 1'no', 2 - 'yes, but very little', 3-'yes, partly', 4 - 'yes to a large extent' and 5 - 'yes to a very large extent'. We also conduct a robustness check in which we dummy-coded the philanthropy variable $(0$ - no charitable giving, 1 - charitable giving, i.e. collapsing the points 2 thru 5 of the Likert scale). This variable reduces the available variance captured in the 5point scale but is a more robust measure, in the sense that it eliminates possible response-bias due to different interpretations of the scale points 2 to 5 .

Entrepreneurial Orientation (EO). EO was measured with a questionnaire widely used and validated in prior research (e.g., Covin and Slevin 1989; Miller and Friesen 1983; Rauch et al. 2009). Entrepreneurs rated their firm's strategic emphasis on innovation, risk-taking and pro-activity using several bi-polar statements (see Appendix for items). More specifically we used items suggested by Covin and Slevin (1989) supplemented by two additional items regarding innovation, and one item each for risk-taking and pro-activity as suggested by for instance Lumpkin Cogliser and Schneider (2009) and Moreno and Casillas (2008) ${ }^{6}$.

Lumpkin and Dess (1996) suggested two further components of EO: autonomy and competitive aggressiveness. Autonomy is understood to be more an enabler or a precondition of EO (e.g. Kuratko et al. 2005; Morris et al. 2007). Competitive aggressiveness shows conceptual overlap with pro-activity, i.e. being the first in a market and ahead of competition. However, the theoretical foundation for an aggressive stance towards competitors as a defining feature of an entrepreneurial firm orientation is less clear. Research on organizational

\footnotetext{
${ }^{6} \mathrm{~A}$ limitation of the data is that one item of the Covin and Slevin's (1989) item measuring pro-activity ("In dealing with its competitors my company, typically seeks to avoid competitive clashes, preferring a 'live-and-let live' posture vs. typically adopts a very competitive 'undo-the competitors' posture.”) was not included.
} 
networking and open innovation suggests that collaboration with competitors can also be considered to be entrepreneurial (e.g. Chiaromonte, 2006).

There has been some debate in the literature whether EO should be conceptualized as three separate dimensions or whether they form an integrated whole (e.g., Covin and Slevin 1989; Lumpkin and Dess 1996; Covin and Lumpkin, 2011). Most studies treat EO as one dimension (e.g. Rauch et al. 2009). Given the theoretical background which defines innovation, pro-activity and risk-taking as components of EO and given the fact that prior research finds these components to co-vary, we conceptualize EO as a second-order factor consisting of three distinguishable, yet related first-order factors (Covin and Wales, 2012). In line with Covin and Wales's (2012) review of the measurement of EO, we specify a hierarchical factor model (Figure 1) with both reflective first- and second-order constructs. This is a model with innovativeness, pro-activeness and risk-taking represented as first-order factors loading on the second-order factor of entrepreneurial orientation. We employed confirmatory factor analysis to test this model, using AMOS 18 (Arbuckle 2009). The specified model fitted the data reasonably well with $\mathrm{Chi}^{2}=130.55(d f=51)$ and $\mathrm{CFI}=.93$. TLI $=.91$, and GFI $=.93$ all exceeding the .90 cut-off criterion (Hu and Bentler, 1995; 1999). RMSEA was .076, exceeding the suggested upper threshold of .06 (Hu and Bentler, 1999). After eliminating items which showed cross-loadings, a more parsimonious model (see Figure 1) based on 9 items, showed an excellent model fit with $\mathrm{Chi}^{2}=45.72(d f=24)$ and $\mathrm{CFI}=.97, \mathrm{TLI}=.96$, and GFI $=.96$ all exceeding the .90 and even the stricter .95 cut-off criterion (Hu and Bentler, 1995; 1999). RMSEA was .058 and as such lower than the recommended maximum of .06 (Hu and Bentler, 1999) again indicating a good model fit. All items loaded substantially and significantly $(\mathrm{p}<.001)$ onto their corresponding first-order factor, i.e. on innovation, pro-activity and risk-taking. The first-order factors in turn loaded substantially and significantly $(\mathrm{p}<.001)$ onto a second-order Entrepreneurial Orientation factor 
(see figure 1 for all factor loadings). The Cronbach's Alpha for this 9-item entrepreneurial orientation scale was .82 (and thus better than for the 12-item EO scale .75).

Insert Figure 1 about here

The Appendix contains the list of retained items. In contrast to the original Covin and Slevin's (1989) scale, the retained items for innovation include not only aspects of product/service innovation but also process innovations. The risk-taking scale consists of the three items suggested by Covin and Slevin (1989). The pro-activity scale also closely resembles the original Covin and Slevin (1989) scale except for one item. This item emphasizes following the leader or being ahead of competition in introducing new products or ideas. It is conceptually consistent with the theoretical background of the scale. We see that as an advantage: increasing 'variety of operationalizations' may help to 'establish the convergent validity of measures' of the underlying theoretical concept of EO (Miller, 2011). Moreover, Rauch et al. (2009) showed that the association of EO with firm performance is relatively unaffected by the specific measurement scale used. Thus, our measure contains validated items of closely related EO measures: we use a content valid scale to measure EO.

Control variables. There are a range of possible alternative explanations for engagement in philanthropy. For instance, it could be that better performing firms simply can afford to engage in philanthropy, while poorly performing firms cannot. Further, exposure to Western-style philanthropy through international links could increase firms' propensity to engage in philanthropy itself. Both firm performance and internationalization are also associated with EO, therefore by including them we eliminate an omitted variable bias.

Financial resources and a firm's performance. In line with prior research we use a subjective measure of 'satisfaction with capital availability' as it is difficult to obtain objective measures of whether or not available capital is sufficient for SMEs (Wiklund, 1999). Owner-managers rated their company's access to financial capital on a 7-point scale from 1 - 
'Insufficient and a great impediment for our development', to 7 - 'Fully satisfactory for the firm's development'. Wiklund and Shepherd (2005) provide convergent and discriminant validation of this measure.

We measure past firm performance using an index of two items, one measuring the change in sales turnover over the past 12 months ('turnover' hereafter) and the second capturing change in net sales profit over the past 12 months ('profit' hereafter). Respondents rated both on a 5-point scale ranging from 1 - 'decrease a lot (more than $-40 \%$ ) to 5 'increase a lot (more than 40\%)'. The Cronbach's Alpha for this two item index was $0.73 .{ }^{7}$

Internationalization. Firm internationalization was measured by two questions capturing two aspects of internationalization, i.e. foreign direct investment and ownership, and exporting of goods or services. The first question asked about the extent to which the firm has attracted investments from abroad over the past 12 months (foreign direct investment, FDI). The owner-managers answered using a 5-point scale from 1-'no', 2-'yes, but very little', 3-'yes, partly', 4-'yes to a big extent' and 5-'yes, to a very big extent'. The second question captured the long-term change in export share. Owner-managers rated on a 5-point scale how their export share developed over the past three 3 years with 1 meaning 'decrease a lot (more than $-40 \%$ ) to 5 'increase a lot (more than $40 \%$ )'.

EO has been found to be a more 'effective' strategy for smaller businesses (Rauch et al. 2009) hence we control for firm size using the number of permanent full-time employees. Similarly, we control for firm age (in years) since younger firms are often considered to be more entrepreneurial. Both firm size and age showed a skewed distribution, thus adhering to protocols outlined by Tabachnick and Fidell (2007) we log-transformed both variables to avoid biased results. Moreover, industry branch was controlled for by using dummy variables for retail trade, wholesale trade, construction and manufacturing.

\footnotetext{
${ }^{7}$ We also conducted a robustness check substituting this index with the owners' subjective appraisal of performance. We did not, however, include this subjective item in our firm success index as it showed only low correlations with turnover and sales. Thus the subjective success assessment captures a distinct aspect of firm performance, which justifies its use as a robustness check. The results remained unchanged and further details are available upon request.
} 


\section{Test for common method bias}

Concerns about common method bias (CMB) arise when all variables in a study are collected through self-report as reports may be biased by respondents' feelings or desirability bias rather than reflect the true nature of things (Podsakoff et al., 2003; Podsakoff and Organ, 1986). CMB is of particular concern when feelings or attitudes are reported. This is not the case in our study where all variables refer to the firm and not to the reporting person him/herself. In addition, most variables in our model are reports of past behaviors (including philanthropy) or reflect objective firm performance information. Nevertheless, we conducted the widely used Harman's common factor test via exploratory factor analysis to assess the extent to which our result may be biased by common method variance. As a rule of thumb, if the common factor explains more than half of the variance amongst all items, then common method variance is said to be a problem. We found that less than a quarter, $22.9 \%$ of the variance was shared among all items. Thus $\mathrm{CMB}$ is unlikely to be an alternative explanation for our findings.

\section{Analysis strategy}

We present results of structural equation modeling which combines factor analysis with the regression approach and has the advantage of explicitly taking measurement errors and inter-correlations among predictors into account (e.g. Kline 2005). As a robustness check, we repeated the analysis using ordered probit regression estimations. The results are highly similar and lead to no different conclusions from the ones presented here. These are available upon request from the authors. 


\section{Results}

We first present our main results based on the quantitative analyses of the survey of 270 SMEs, and next we extend it based on qualitative data from 10 in-depth follow-up interviews.

EO and philanthropy: results based on quantitative analysis

Descriptive statistics and simple correlations for all the variables are displayed in Table 1. They indicate that philanthropy is surprisingly common among SMEs in Lithuania: $53 \%$ of Lithuanian SMEs engaged in some form of philanthropy over the past year.

Insert Table 1 about here

In formal testing of hypotheses we rely on structural equation modeling. Figure 2 and Table 2 display the results of regressing philanthropy on EO, controlling for potential covariates (access to finance, past firm performance, internationalization, firm size, firm age and industry sector). Overall $25 \%$ of the variance of a firm's philanthropic orientation was explained by this predictor and set of control variables. The model fitted the data well with $\mathrm{Chi}^{2}=191.19(d f=130)$ and $\mathrm{CFI}=.95, \mathrm{TLI}=.93$, and GFI $=.94$ all exceeding the .90 and partly the stricter .95 cut-off criterion (Hu and Bentler, 1995; 1999). RMSEA was .042 and as such lower than the recommended maximum of .06 (Hu and Bentler, 1999), indicating good model fit.

Insert Figure 2 and Table 2 about here

Entrepreneurial orientation (EO) was significantly related to the SMEs' philanthropy $(ß=.27, p<.01$, see figure 2 and table 2$)$. As a robustness check we substituted the dummycoded philanthropy variable for the continuous philanthropy measure. The relationship of philanthropy and EO remains significant albeit somewhat reduced $(\beta=.17, p<.05)$, which is to be expected as dummy-coding reduces the variance of the philanthropy measure. 
EO and philanthropy: insights from additional in-depth interviews

In additional interviews we probed in more detail the motivations underlying philanthropy efforts (and the lack of such effort) by SMEs with medium to high EO (defined as values at or above the sample mean of EO). We selected both the SMEs who were and who were not engaged in philanthropy.

When asked about their motivations and the benefits that they receive from philanthropy, it was notable that a range of benefits and reasons were cited consistent with the mechanisms reviewed in the theoretical framework. On the one hand, the owner-managers recognized benefits from philanthropy in terms of increased legitimacy. For example, the owner-manager of an insurance services firm sponsoring children in need declared:

"For our company there is one big benefit - in costumer eyes we are good and helpful company... people see that we are helping children and they may choose our company services but not competitors who don't help anyone."

Similarly, probed about the potential business benefits of their philanthropy, the owner-manager of a construction company, which also supported children with special needs, stated:

"Hhm, maybe yes. If I think deeper then I can say yes, because in costumer and supplier eyes we look better, if we are helping someone.....yes we can get better relationship with government if we are helping someone... Yes, local government also like when companies are helping someone. So this also helps us to have good relationship with government."

Yet at the same time probed for benefits with regard to the company's competitiveness, the respondent dismissed the importance of instrumental motives using the following words: 
“... this is simply sponsorship for children. It's not a part of our business. So we can't become more competitive because we help someone."

In a similar fashion, the owner-manager of a retail (cosmetics) company that supports a sport-team replied the following when asked about (instrumental) benefits of philanthropy: "I think there are not any benefits for the company, because we are giving away money and they don't come back...."

When probed further for whether or not there are any business benefits from the philanthropy engagement he mentioned:

"I think more no then yes. Maybe our company becomes more recognizable, but it's only very, very small part of all things that we need to be more competitive." Another owner-manager of an ICT service company that works in an ethical and responsible manner and supports a similar smaller company did not see any legitimacy benefits. However, he mentioned other indirect and longer-term business benefits that are consistent with the notion of philanthropy, in particular building social capital in the form of building up general norms of cooperation, as contrasted with (direct) instrumental benefits:

"The motivation is simple - if you will help someone than when you will need some help, someone will help you. All good things come back."

"We don't have any [business] benefits."

Thus some of the above responses - i.e. those that see helping others through philanthropy as an obligation - suggest that altruistic values are a driver of philanthropy in addition to instrumental-strategic considerations. Indeed, altruistic motives including the notion that philanthropy was the "right thing to do" were a recurring theme as the following quotes illustrate:

"I think helping children... it's a big moral benefit for you as human and also for company.... We are getting moral benefits from this sponsorship." (owner-manager of the construction company); 
"I think every company should sponsor someone if they have some free resources." (owner-manager of a retail cosmetics firm; in response to the question whether companies have an obligation to engage in philanthropy);

"Because children need help more than others and I think if we can help than it's our obligation. If we can, we always will help.” (spontaneous answer of the ownermanager of the insurance services firm when asked about his reason for engaging in philanthropy); and

"I think companies should sponsor social needs. But if they cannot than is not something bad.....It's not correct to help someone only if you will have some benefits. It's very bad I think." (the same owner-manager when asked whether businesses have an obligation to engage in philanthropy and whether there needs to be a business case or benefit for them).

Interestingly the views of those SMEs who were currently not engaged in philanthropy stressed free choice - no obligation to engage in philanthropy - often alongside instrumental motives including legitimacy and business opportunities. They did not refer to altruistic motivations. The following quotes illustrate this:

"Yes of course it [philanthropy] is part of business. When you are sponsoring someone your company becomes much better in customers eyes and because of that you have opportunity to get new customers." (owner-manager of an advertising company);

“No [we don't engage in philanthropy], because it's not profitable. Because of our country laws, sponsorship is not profitable. We need to pay big taxes for government. If taxes wouldn't be so big than our company would sponsor someone....it's no obligation to sponsor someone, if you don't want to do that. It's your choice." (owner-manager of a cargo shipping company); 
“If you don't get some [business] benefits from sponsorship than it's not reasonable to sponsor someone." (owner-manager of a plastic products company);

“it's every company's free choice. If you want you will engage in sponsorship, but if no than no..... if you will get some benefits than yes." (owner-manager of a wholesale food products company); and “...it's not obligated and we don't want to do that. You can sponsor someone if you need to launder some money.” (owner-manager of a financial services firm).

\section{Further findings}

Further findings from quantitative research. Both measures of internationalization the attraction of foreign direct investment and export share - were positively associated with the SMEs' philanthropy at $p<.10$. Firm size (natural log of the number of employees) was positively related to SMEs' philanthropy at $\mathrm{p}<.01$ (as well as to their EO). Thus, bigger and more internationalized firms seemed to be more inclined to make a positive contribution to society. At the same time, past firm performance and access to finance - indicators that capture the availability of resources - were not significantly related to philanthropy.

Further insights from in-depth interviews. The in-depth interviews shed an interesting light on the lack of findings around slack resources. The SMEs not engaged in philanthropy commented much in line with the slack resources view "without money you can't do anything like that" (owner-manager of wholesale trade food products company), "we don't have the money for that, we need money for our company needs ... without money you can't do anything... firstly we need to resolve our problems and then we will start think about sponsorship" (owner-manager of a car diagnostics firm), "money rules the world" (ownermanager of a financial services firm). Similarly, when asked why other companies do not engage in philanthropy, lack of resources where cited (e.g., "don't have money”, "don't have resources") along with "don't want that”. 
By contrast, the SMEs engaging in philanthropy showed a broader understanding of resources, in that resources other than money can be helpful and thus monetary constraints would not necessarily limit their philanthropy. This is illustrated in the following quotes " $I$ can help people also without money.” (owner-manager of a retail cosmetics firm), "Our company is an example how companies can help without money." (owner-manager of an insurance services firm), and “I think if you don't have money than it's very hard to help someone, because in nowadays everyone need money to do something. But there are also things that you can do without money." (owner-manager of a construction company).

\section{Discussion}

This study provides novel evidence that more entrepreneurially oriented small and medium-sized enterprises (SMEs) are also more likely to engage in philanthropy (charitable giving). We find that philanthropy is common among SME owner-managers (just over half of the representative sample of SMEs engaged in philanthropy).

Our findings complement and extend existing research on entrepreneurial philanthropy by demonstrating that philanthropy can be simultaneous with entrepreneurship rather than sequentially following after entrepreneurs achieved wealth and success, and by highlighting that the entrepreneurship-philanthropy relationship can even be found in an institutional context where historically support for both entrepreneurship and philanthropy have been weak.

Our results also have more general implications for research on entrepreneurial motivation. They highlight the multi-facetted motivations underlying SMEs philanthropic engagement and thereby add to the growing literature that challenges views of entrepreneurs as one-dimensional, self-interested actors. Finally, our results also add to the literature on Entrepreneurial Orientation (EO) extending it to societal outcomes. 


\section{Contributions to research on entrepreneurial philanthropy}

Our findings extend the existing research on entrepreneurial philanthropy (Acs and Phillips, 2002; Shaw et al., 2013) from high net-worth elites to typical SME owner-managers. Thus, philanthropy is not just "the responsibility" of the very rich (Acs and Phillips, 2002) taken up after economic wealth is generated. Philanthropy is also a tool for entrepreneurial SMEs to fit in and build legitimacy in their communities, and importantly, an expression of entrepreneurs' altruistic values. Philanthropy by elite entrepreneurs is attention-catching, while the philanthropy of SMEs is smaller in scale. However, the latter may over the longer term be just as important, not just for the businesses but also for the communities the SMEs are based in, building local social capital - an informal institution that is poorly developed in transition economies like Lithuania. In this way our study, more broadly, sheds some light on the micro-level mechanisms of bottom-up institutional change.

Our qualitative findings suggest altruism as one driving force of entrepreneurs' philanthropy. This emphasizes that research on philanthropy has a connection with research on social entrepreneurship, as there is a common link related to entrepreneurs' motivational values. More generally, the positive link between entrepreneurial SMEs and philanthropy adds to notions that private for-profit and private non-profit activities can be mutually reinforcing (Acs and Phillips, 2002; Estrin et al., 2013; Van der Ven et al., 2007) rather than present two mutually exclusive logics.

\section{Analyzing the entrepreneurship-philanthropy link in a novel context}

We also extend existing research on entrepreneurial philanthropy by investigating it in a post-Soviet transition economy, Lithuania. Thus, our findings highlight that philanthropy is not unique to rich economies such as the UK and U.S. Instead, it surfaces in a context characterized by a cultural legacy alien to both entrepreneurship and independent, decentralized social initiatives such as philanthropy (Estrin and Mickiewicz, 2011; Schwartz 
and Bardi, 1997). Thus, finding these positive relationships of EO with philanthropy in the Lithuanian context is striking. While the process of change in informal institutions and culture is typically seen as slow (North, 1990; Inglehart, 2008), our results suggest that this change it is taking place.

This evolution may be driven both by the strategic choices of owner-managers seeking legitimacy and building synergies with local knowledge, and - on a more fundamental plane reflecting the above mentioned value-pattern (emphasizing both prosociality and openness to change), which appears to be universally shared (Schwartz and Bardi, 2001) - and therefore may be less difficult to restore after Communism than one could think. Fundamentally, change through strategic choices and change in value-patterns do not need to be mutually exclusive: what is legitimate is affected by prevalent norms.

For Lithuania, our findings imply that the country is moving in the direction which is arguably consistent with an entrepreneurial-based economic development trajectory. This is further corroborated by our findings that philanthropy is most supported where firms are most internationalized; although the positive effect of internationalization on SMEs' philanthropic engagement is weaker than the effect of EO.

\section{The multi-facetted nature of entrepreneurial motivation}

This study contributes to research emphasizing the complex nature of entrepreneurial motivation (e.g., Gorgievski et al., 2011; Jaywarma, Rouse \& Kitchen, 2011; Lang et al., 2014). Our finding of a mutually reinforcing (rather than competing) relationship of EO with pro-social behavior such as philanthropy offers an extension of fundamental psychological theories of human motivation (e.g. Schwartz, 1992) to entrepreneurship. Evidence is accumulating that people across cultures share values related to both pro-sociality (related to philanthropy) and openness to change (a key entrepreneurial trait; see: Noseleit, 2010); both are strongly endorsed across countries (Schwartz and Bardi, 2001). Importantly, these two 
clusters of values are repeatedly found to be positively related to each other, as both imply intrinsic motivations (e.g. Schwartz, 1992; 2009). Our study offers evidence reinforcing this association for entrepreneurs.

Our findings suggest that the philanthropy of typical SME owner-managers may actually be an expression of their altruistic values. We also see evidence that other-regarding motivation is associated with long-term orientation (e.g. the long-term building of local social capital and generalized reciprocity), consisted with findings on the characteristics of 'givers' in business (e.g., Grant, 2014).

Interestingly those entrepreneurs not engaged in philanthropy particularly highlighted its instrumental, strategic benefits and pointed to resource constraints as a barrier to engaging in philanthropy. Thus existing academic theories emphasizing the instrumental-strategic perspective and resource constraints may at least in part also be a reflection of the rationalizations of those business owners who do not engage in philanthropy.

In this regard our study has also wider implications for business research. As observed by DiMaggio (1988) and Oliver (1991) self-interested behavior of firms tends to be assumed in business research instead of being theorized explicitly. Addressing these gaps in the literature, we first provide evidence of heterogeneity in entrepreneurs' motivation that includes both the strategic-instrumental self- regarding and the other-regarding intrinsic-value based aspects. Second, and more importantly, we point out that the association of the entrepreneurial orientation and other-regarding orientation (as exemplified by philanthropy) is less paradoxical as it appears, as soon as we draw upon the overarching intrinsic aspect that links innovativeness to other-regarding motivation, based on Schwartz (1992) systematization of human values map. This has wider implications, and calls for further research on the role of self-oriented and self-transcending values as drivers of entrepreneurship. 


\section{Contributions to research on Entrepreneurial Orientation (EO)}

Our findings also add to the large body of research on EO. This literature has successfully focused on establishing economic outcomes of EO (e.g., Rauch et al., 2009; Wales et al., 2013a). Our research offers an extension by highlighting that positive social outcomes, such as philanthropy may arise from strong EO. Philanthropy helps entrepreneurial firms to build legitimacy, compensating for newness and potentially leading to synergies in the use of local knowledge. While legitimacy effects are well established, future research could explore the synergetic effects further. Entrepreneurially-oriented SMEs may benefit from the distinct knowledge that they could access via philanthropic engagement for instance with non-profit organizations (Acs and Braunerhjelm 2004). Moreover, there may be a strong synergy between the access to additional knowledge and the capacity to utilize this knowledge effectively by those SMEs that are most entrepreneurial (EO). This makes seeking additional knowledge via strengthening links with the local community an attractive strategy for entrepreneurially oriented firms. Conversely, non-profit initiatives may benefit from knowledge transfers that accompany the financial transfers (Acs and Braunerhjelm 2004), which is one of the examples of benevolent transfer of non-monetary resources our respondents hinted at in our in-depth interviews. Finally, voluntary associations also create a social milieu where entrepreneurial networks are formed, further supporting for-profit initiatives (Estrin et al., 2013).

Our results on the significant relationship between EO and philanthropy are made sharper by the fact that we control for alternative explanations. With regard to these, our findings are also at odds with the literature on corporate philanthropy. The latter reports that past performance and slack resources are positively related to firms philanthropy (Orlitzky et al., 2003; Wang and Qian, 2011). We fail to find such a relationship, and the in-depth followup interviews suggest one possible reason why. It appears that one of the hallmarks of entrepreneurial action - making creative use of existing scarce resources (Baker and Nelson, 
2005) - also plays out for philanthropy. Philanthropy need not be constrained by lack of financial resources and entrepreneurs for whom philanthropy is consistent with their values find other ways of giving. Again, our findings are only tentative and future research is needed to explore these issues in more depth.

\section{Limitations}

We see our study as an exploratory one. Even though we could draw on a representative sample of SMEs in Lithuania and thereby shed light on the philanthropic engagement of typical SMEs, the cross-sectional nature of our data implies caution in forming any judgments on causality. We believe that the questions we address are novel, yet we face data limitations. Future studies could test more rigorously which driver of philanthropy (strategic or altruistic) is most common among SMEs and, importantly, what the differences in outcomes may be. We need to build a richer understanding of what motivates SMEs to engage in philanthropy, but also of the effects that philanthropy has on the SMEs themselves, for the community and ultimately for those who receive it. Future research could also explore in more depth the tangible benefits that entrepreneurs obtain from contributing to civic society, such as legitimization in the eyes of the key stakeholders as well as access to information spill-overs and networking. Moreover, the present study includes one aspect of social firm performance that is giving to charity. Future studies can extend the present findings by analyzing the association with different aspects of corporate social performance in addition to philanthropy, such as business practices relating to environmental behavior, treatment of shareholders and co-owners, employees, customers and suppliers (e.g., Campbell 2007).

\section{Conclusion}

While our results are of novel and preliminary nature, we believe that the findings may have wider implications for future research. The traditional focus on self-interest in 
entrepreneurship might need rethinking. Private initiative contains a strong social element; successful examples of entrepreneurship are characterized not by lonely efforts of individuals but by interaction with the local social context, which often provides critical resources to small and starting firms in general and to dynamic firms in particular (Efendic et al. 2014; Stephan and Uhlaner, 2010). Indeed, it is this capacity for (local) self-organization which is at the core of both economic initiative and civic society (Estrin et al., 2013). If one accepts that entrepreneurs are not one-dimensional self-centered actors, but are at the same time embedded in local communities (Evans, 2001), the link between economic initiative and civic society is to be expected. Applying psychological value theory (Schwartz, 1992) leads us to similar conclusions: the association between the other-regarding and entrepreneurial, innovative behavior stems from common underlying intrinsic motivations. We hope future research explores corresponding predictions (Grant, 2014) that other-regarding ('giving') behavior may lead to higher long-term economic benefits for SMEs than an instrumental, narrower focus on self-interest ('taking'). 


\section{References}

Acs Z and Braunerhjelm P (2005) The entrepreneurship-philanthropy nexus: Implications for internationalization. Management International Review 45: 111-144.

Acs Z and Dana L (2001) Contrasting two models on wealth redistribution. Small Business Economics 16: 63-74.

Acs Z and Phillips R (2002) Entrepreneurship and philanthropy in American capitalism. Small Business Economics 19: 189-204.

Aidis R and Mickiewicz T (2006) Entrepreneurs, expectations and business expansion: lessons from Lithuania. Europe-Asia Studies, 58: 855-880.

Aidis R and van Praag M (2007) Illegal entrepreneurship experience: does it make a difference for business performance and motivation? Journal of Business Venturing, 22: 283-310.

Amato CH and Amato LH (2011) Corporate commitment to global quality of life issues: Do slack resources, industry affiliation, and multinational headquarters matter? Business and Society, 50: 388-416.

Arbuckle JL (2009) Amos 18. Crawfordville, FL: Amos Development Corporation.

Baker T and Nelson RE (2005) Creating Something from Nothing: Resource Construction through Entrepreneurial Bricolage. Administrative Science Quarterly, 50, 329-366.

Baker WE and Sinkula JM (2009) The complementary effects of market orientation and entrepreneurial orientation on profitability in small businesses. Journal of Small Business Management 47: 443-464.

Bardi A and Schwartz SH (2001) Value hierarchies across cultures. Journal of Cross-Cultural Psychology, 32: 268-290,

Battilana J and Lee M (2014) Advancing Research on Hybrid Organizing - Insights from the Study of Social Enterprises. Academy of Management Annals, 8, 397-441.

Bekkers R and Wiepking P (2011) A literature review of empirical studies of philanthropy: Eight mechanisms that drive charitable giving. Nonprofit and Voluntary Sector Quarterly 40: 924-873.

Boettke P and Rathbone A (2002) Civil society, social entrepreneurship, and economic calculation: Towards a political economy of the philanthropic enterprise. The Philanthropic Enterprise, Working Paper No 8.

Campbell JL (2007) Why would corporations behave in socially responsible way?: An institutional theory of corporate social responsibility. Academy of Management Review 32: $946-967$.

Carroll A (1991) The pyramid of corporate social responsibility: Toward the moral management of organizational stakeholders. Business Horizons, July/August: 225-235.

Chiaromonte F (2006) Open innovation through alliances and partnership: theory and practice. International Journal of Technology Management 33: 111-114.

Covin JG and Lumpkin GT (2011) Entrepreneurial orientation theory and research: Reflections on a needed construct, Entrepreneurial Theory and Practice 35: 855-872.

Covin JG and Miles MP (1999) Corporate entrepreneurship and the pursuit of competitive advantage. Entrepreneurship Theory and Practice 33: 47-63.

Covin JG and Slevin DP (1989) Strategic management of small firms in hostile and benign environments. Strategic Management Journal 10: 75-87.

Covin JG and Wales WJ (2012) The measurement of entrepreneurial orientation. Entrepreneurship Theory and Practice 36: 677-702

Devereaux Jennings P, Greenwood R, Lounsbury M and Suddaby R (2013) Institutions, entrepreneurship, and communities: A special issue on entrepreneurship. Journal of Business Venturing 28: 1-9. 
DiMaggio PJ (1988) Interest and agency in institutional theory. In Zucker LG (Ed.) Institutional patterns and organizations: Culture and environment. Cambridge, MA: Ballinger: 3-21.

Drucker PF (1985) Innovation and entrepreneurship. New York, NY: Harper Perennial.

Efendic A, Mickiewicz T, Rebmann A (2014) Growth aspirations and social capital : Young firms in a post-conflict environment. International Small Business Journal, doi:10.1177/0266242613516987.

Estrin S and Mickiewicz T (2011) Entrepreneurship in transition economies: The role of institutions and generational change. In: The Dynamics of Entrepreneurship, Minniti M. (ed.). Oxford University Press: Oxford; 181-208.

Estrin S, Mickiewicz T, Stephan U (2013) Entrepreneurship, social capital, and institutions: Social and commercial entrepreneurial activity across nations. Entrepreneurship Theory and Practice 37: 479-504.

Evers A (2001). The significance of social capital in the multiple goal and resource structure of social enterprises. In Borzaga $\mathrm{C}$ and J Defourny, (Eds.), The Emergence of Social Enterprise, London and New York, Routledge

Gorgievski MJ, Ascalon ME, Stephan U (2011) Small business owners' success criteria, a values approach to personal differences. Journal of Small Business Management 49: 207-232.

Goyal A (2006) Corporate social responsibility as a signaling device for foreign direct investment. International Journal of the Economics of Business 13: 145-163.

Grant A (2014) Give and Take. Phoenix: London.

Guriev S and Zhuravskaya E (2009) (Un)Happiness in transition. Journal of Economic Perspectives 23: 143-168.

Hansen JD, Deitz GD, Tokman M, Marino LD, Weaver KM (2011) Cross-national invariance of the entrepreneurial orientation scale. Journal of Business Venturing 26: 61-78.

Hess M (2004) 'Spatial'relationships? Towards a reconceptualization of embeddedness. Progress in Human Geography, 28: 165-186.

Hu L and Bentler PM (1995) Evaluating model fit. In Structural Equation Modeling: Concepts, Issues and Applications, Hoyle RH (ed). Sage: London; 76-99.

$\mathrm{Hu} \mathrm{L}$ and Bentler PM (1999) Cutoff criteria for fit indexes in covariance structure analysis: Conventional criteria versus new alternatives. Structural Equation Modeling 6:1-55.

Inglehart R (2008) Changing values among western publics from 1970 to 2006 . West European Politics 31: 130-146.

Jayawarna D, Rouse J and Kitching J (2011) Entrepreneur motivations and life course. International Small Business Journal, 31: 34-56.

Kline R (2005) Principles and Practice of Structural Equation Modeling. Guildford Press: New York.

Kreiser PM, Marino LD, Weaver KM (2002) Assessing the psychometric properties of the entrepreneurial orientation scale: A multi-country analysis. Entrepreneurship Theory and Practice 26: 71-94.

Kuratko DF, Ireland RD, Covin JG, Hornsby JS (2005) A model of middle-level managers' entrepreneurial behavior. Entrepreneurship Theory and Practice 29: 699-716.

Lang R, Fink M, Kibler E (2014) Understanding place-based entrepreneurship in rural Central Europe: A comparative institutional analysis. International Small Business Journal 32: 204-227.

Lee, M-D P (2008) A review of the theories of corporate social responsibility: Its evolutionary path and the road ahead. International Journal of Management Reviews 10: 53-73.

Lumpkin GT and Dess GG (1996) Clarifying the entrepreneurial orientation construct and linking it to performance. Academy of Management Review 21: 135-172. 
Lumpkin GT, Cogliser CC, Schneider DR (2009) Understanding and measuring autonomy: An entrepreneurial orientation perspective. Entrepreneurship Theory and Practice 33(1): 47-69.

Luo Y and Junkunc M (2008) How private enterprises respond to government bureaucracy in emerging economies: The effects of entrepreneurial type and governance. Strategic Entrepreneurship Journal 2: 133-153.

Mair J and Hehenberger L (2013). Front Stage and Back Stage Convening: The Transition from Opposition to Mutualistic Coexistence in Organizational Philanthropy. Academy of Management Journal DOI 10.5465/amj.2012.0305.

Mair J and Marti I (2006) Social entrepreneurship research: A source of explanation, prediction, and delight. Journal of World Business, 41: 36-44.

Mickiewicz T (2010) Economics of Institutional Change. Houndmills: Palgrave Macmillan.

Miller D (1983) The correlates of entrepreneurship in three types of firms. Management Science 29: 770-791.

Miller D (2011) Miller 1983 revisited: A reflection on EO research and some suggestions for the future. Entrepreneurship Theory and Practice 35: 873-894.

Miller D and Friesen PH (1983) Strategy-making and environment: The third link. Strategic Management Journal 4: 221-235.

Moreno AM and Casillas JC (2008) Entrepreneurial orientation and growth of SMEs: A causal model. Entrepreneurship Theory and Practice 32: 507-528.

Morris MH, Coombes S, Schindehutte M, Allen J (2007) Antecedents and outcomes of entrepreneurial and market orientations in a non-profit context: Theoretical and empirical insights. Journal of Leadership and Organizational Studies 13: 12-39.

Muller AR, Pfarrer MD, Little LM (2014) A Theory of Collective Empathy in Corporate Philanthropy Decisions. Academy of Management Review, 39: 1-21.

North D (1990) Institutions, Institutional Change and Economic Performance. New York: Cambridge University Press.

Noseleit F (2010) The entrepreneurial culture: Guiding principles of the self-employed. In: Freytag A and Thurik R (eds), Entrepreneurship and Culture, Berlin, Heidelberg: Springer, pp. 41-54.

Oliver C (1991) Stretegic responses to institutional processes. Academy of Management Review 16(1): 145-179.

Orlitzky M, Schmidt FL, Rynes SL (2003) Corporate social and financial performance: A meta analysis. Organization Studies 24: 403-411.

Peng, M (2000) Business Strategies in Transition Economies. Thousand Oaks: Sage.

Pistrui D, Welsch H, Wintermantel O, Liao J, Pohl H (2000) Entrepreneurial orientation and family forces in new Germany: Similarity and differences between east and west German entrepreneurs. Family Business Review 13: 251-263.

Podsakoff PM, MacKenzie SB, Lee J-Y, Podsakoff NP (2003) Common method biases in behavioral research: A critical review of the literature and recommended remedies. Journal of Applied Psychology 88: 879-903.

Podsakoff PM and Organ DW (1986) Self-reports in organizational research: Problems and prospects. Journal of Management 12: 532-544.

Putnam, RD (1995) Bowling alone: America's declining social capital. Journal of Democracy 6: $65-78$.

Rauch A, Wiklund J, Lumpkin GT, Frese M (2009) Entrepreneurial orientation and business performance: An assessment of past research and suggestions for the future.

Entrepreneurship Theory and Practice 33: 761-787.

Schumpeter JA (1934) Theorie der wirtschaftlichen Entwicklung [Theory of Economic Development]. Duncker and Humblot: Berlin. 
Schwartz SH (1990) Individualism-collectivism: critique and proposed refinements. Journal of Cross-Cultural Psychology 21: 139-157.

Schwartz SH (1992) Universals in the content and structure of values: Theoretical advances and empirical tests in 20 countries. Advances in Experimental Social Psychology 25(1): $1-65$.

Schwartz SH (2009) Basic Values: How they motivate and inhibit prosocial behavior. In Herzliya Symposium on Personality and Social Psychology, Mikulincer M, Shaver P (eds) American Psychological Association Press: Washington; Vol. 1.

Schwartz SH and Bardi A (1997) Influences of adaptation to communist rule on value priorities in Eastern Europe. Political Psychology, 18: 385-410.

Schwartz SH and Bardi A (2001) Value hierarchies across cultures: Taking a similarities perspective. Journal of Cross-Cultural Psychology, 32: 268-290.

Shaw, E., Gordon, J., Harvey, C., Maclean, M (2013) Exploring contemporary entrepreneurial philanthropy. International Small Business Journal 31(5): 580-599

Short JC, Broberg JC, Cogliser CC, Brigham KH (2009) Construct validation using Computer-Aided Text Analysis (CATA): An illustration using entrepreneurial orientation. Organizational Research Methods 13: 320-347.

Stephan U and Uhlaner L (2010) Performance-based vs. socially-supportive culture: A crossnational study of descriptive norms and entrepreneurship. Journal of International Business Studies 41: 1347-1364.

Suchman MC (1995) Managing legitimacy: Strategic and institutional approaches. Academy of Management Review 20: 571-610.

Tabachnick BG and Fidell LS (2007) Using Multivariate Statistics $5^{\text {th }} e d$. Pearson: Boston.

Van de Ven AH, Sapienza HJ, Villaneuva J. (2007). Entrepreneurial pursuits of self- and collective interests. Strategic Entrepreneurship Journal 1: 353-370.

Wales WJ, Gupta VK and Mousa FT (2013a) Empirical research on entrepreneurial orientation: An assessment and suggestions for future research. International Small Business Journal 31(4): 357-383.

Wales WJ, Wiklund J, McKelvie A (2013b) What about new entry? Examining the theorized role of new entry in the entrepreneurial orientation-performance relationship. International Small Business Journal. Doi: 10.1177/0266242613506023.

Wang H, Qian C (2011) Corporate philanthropy and corporate financial performance: The role of stakeholder response and political access. Academy of Management Journal 54: 1159-1182.

Welter F, Smallbone D (2011) Institutional perspectives on entrepreneurial behavior in challenging environment. Journal of Small Business Management 49(1): 107-125.

Wiklund J (1999) The sustainability of the entrepreneurial orientation - performance relationship. Entrepreneurship Theory and Practice 24: 37-48.

Wiklund J and Shepherd D (2003) Knowledge-based resources, entrepreneurial orientation, and the performance of small and medium sized businesses. Strategic Management Journal 24: 1307-1314.

Wiklund J and Shepherd D (2005) Entrepreneurial orientation and small business performance: A configurational approach, Journal of Business Venturing 20: 71-91.

Wiklund J and Shepherd D (2011) Where to from here? EO-as-experimentation, failure, and distribution of outcomes. Entrepreneurship Theory and Practice 35: 925-946.

Wong PK, Ho YP, Autio E (2005) Entrepreneurship, innovation and economic growth: Evidence from GEM data. Small Business Economics 24: 335-350.

Zimmerman MA and Zeitz G (2002) Beyond survival: achieving new venture growth by building legitimacy. Academy of Management Review 27: 414-431. 


\section{Appendix:}

\section{Entrepreneurial Orientation Items}

How many new lines of products or services has your firm marketed in the past 3 years? i1 - No new lines of products or $\quad \begin{array}{lllllllll}1 & 2 & 3 & 4 & 5 & 6 & 7 & \text { Very many new lines of }\end{array}$ services i2 - Changes in product or service

lines have been mostly of a minor nature

i3 (reverse scored) - My firm prefers to design its own unique new processes and methods of production products and services

$\begin{array}{llllllll}1 & 2 & 3 & 4 & 5 & 6 & 7 & \text { Changes in product or service }\end{array}$ lines have usually been quite dramatic

$\begin{array}{llllllll}1 & 2 & 3 & 4 & 5 & 6 & 7 & \text { My firm prefers to adapt for }\end{array}$ our own use methods and techniques that others have developed and proven

Have a strong proclivity for $r 1$ - Have a strong proclivity for low risk projects (with normal and certain rates of return) $r 2$ - Believe that owing to the nature of the environment, it is best to explore it gradually via careful, incremental behavior
$\begin{array}{llllllll}1 & 2 & 3 & 4 & 5 & 6 & 7 & \text { high risk projects (with }\end{array}$ chances of very high returns) Owing to the nature of the $\begin{array}{lllllll}1 & 2 & 3 & 4 & 5 & 6 & 7\end{array}$ environment, bold, wide- ranging acts are necessary to achieve the firm's objectives

r3 - When confronted with decision-making situations involving uncertainty, my firm ... Typically adopts a cautious, 'waitand-see' posture in order to minimize the probability of making costly decisions

aggressive posture in order to

$\begin{array}{llllllll}1 & 2 & 3 & 4 & 5 & 6 & 7 & \text { maximize the probability of }\end{array}$ exploiting potential opportunities

In dealing with its competitors, my firm ...

\begin{tabular}{|c|c|c|c|c|c|c|c|c|}
\hline $\begin{array}{l}\text { p1 - Typically responds to action } \\
\text { which competitors initiate }\end{array}$ & 1 & 2 & & $T$ & 5 & 6 & 7 & $\begin{array}{l}\text { Typically initiates actions } \\
\text { which competitors then } \\
\text { respond to }\end{array}$ \\
\hline $\begin{array}{l}\text { p2 - Is very seldom the first } \\
\text { business to introduce new } \\
\text { products/services, administrative } \\
\text { techniques, operating } \\
\text { technologies, etc. }\end{array}$ & 1 & 2 & 3 & 4 & 5 & 6 & 7 & $\begin{array}{l}\text { Is very often the first business } \\
\text { to introduce new } \\
\text { products/services, } \\
\text { administrative techniques, } \\
\text { operating technologies, etc. }\end{array}$ \\
\hline
\end{tabular}

p3 - In general, the top managers of my firm have . . .
A strong tendency to 'follow the $\quad \begin{array}{llllllll}1 & 2 & 3 & 4 & 5 & 6 & 7 & \text { A strong tendency to be ahead }\end{array}$ leader' in introducing new
products or ideas
of other competitors in introducing novel ideas or products


Table 1

Correlations and Descriptive Statistics

\begin{tabular}{|c|c|c|c|c|c|c|c|c|c|c|c|c|c|c|c|}
\hline & Variables & $\mathrm{M}$ & SD & 1 & 2 & 3 & 4 & 5 & 6 & 7 & 8 & 9 & 10 & 11 & 12 \\
\hline 1 & $\mathrm{EO}$ & 3.95 & 1.02 & & & & & & & & & & & & \\
\hline 2 & Philanthropy & 1.76 & 0.87 & $0.37 * * *$ & & & & & & & & & & & \\
\hline 3 & $\begin{array}{l}\text { Philanthropy - } \\
\text { dummy }\end{array}$ & 0.53 & 0.50 & $0.31 * * *$ & $0.82 * * *$ & & & & & & & & & & \\
\hline 4 & Manufacturing & 0.17 & 0.38 & -0.01 & 0.02 & 0.08 & & & & & & & & & \\
\hline 5 & Wholesale trade & 0.16 & 0.37 & 0.08 & $0.10^{\mathrm{t}}$ & 0.07 & $-0.20 * * *$ & & & & & & & & \\
\hline 6 & Retail trade & 0.10 & 0.30 & 0.04 & 0.02 & -0.03 & $-0.15^{*}$ & $-0.15^{*}$ & & & & & & & \\
\hline 7 & Construction & 0.14 & 0.35 & 0.08 & 0.05 & $0.11^{\mathrm{t}}$ & $-0.19 * *$ & $-0.18 * *$ & $-0.14 *$ & & & & & & \\
\hline 8 & $\begin{array}{l}\text { Size (ln number } \\
\text { employees) }\end{array}$ & 2.40 & 1.00 & $0.27 * * *$ & $0.31 * * *$ & $0.32 * * *$ & $0.19 * * *$ & $-0.12 *$ & $-0.12^{t}$ & 0.30 & & & & & \\
\hline 9 & Age (ln firm age) & 1.73 & 0.33 & -0.02 & 0.09 & 0.09 & -0.01 & 0.03 & 0.05 & $-0.15^{*}$ & $0.10^{\mathrm{t}}$ & & & & \\
\hline 10 & $\begin{array}{l}\text { Past performance } \\
\text { (sales turnover) }\end{array}$ & 3.99 & 1.08 & $0.40 * * *$ & $0.30 * * *$ & $0.31 * * *$ & 0.08 & $0.18 * *$ & -0.08 & $0.10 \mathrm{t}$ & $0.27 * * *$ & -0.10 & & & \\
\hline $\begin{array}{l}11 \\
12\end{array}$ & $\begin{array}{l}\text { Access to finance } \\
\text { Foreign direct }\end{array}$ & 4.56 & 1.76 & $0.30 * * *$ & $0.20 * * *$ & $0.20 * * *$ & 0.08 & 0.04 & -0.08 & $0.12 *$ & $0.22 * * *$ & $-0.11^{\mathrm{t}}$ & $0.29 * * *$ & & \\
\hline 13 & $\begin{array}{l}\text { investment } \\
\text { Export share }\end{array}$ & $\begin{array}{l}0.20 \\
3.19 \\
\end{array}$ & $\begin{array}{l}0.41 \\
0.74 \\
\end{array}$ & $\begin{array}{l}0.15^{*} \\
0.10^{\mathrm{t}}\end{array}$ & $\begin{array}{l}0.19 * * \\
0.17 * *\end{array}$ & $\begin{array}{l}0.16^{* *} \\
0.12 *\end{array}$ & $\begin{array}{l}0.05 \\
0.27 * * *\end{array}$ & $\begin{array}{l}0.05 \\
0.06\end{array}$ & $\begin{array}{c}-0.12 \mathrm{t} \\
0.00\end{array}$ & $\begin{array}{l}-0.06 \\
-0.13 *\end{array}$ & $\begin{array}{l}0.02 \\
0.10^{\mathrm{t}}\end{array}$ & $\begin{array}{r}-0.03 \\
0.06 \\
\end{array}$ & $\begin{array}{l}0.09 \\
0.26 * * *\end{array}$ & $\begin{array}{l}0.12^{*} \\
0.04\end{array}$ & $0.14 *$ \\
\hline
\end{tabular}

$N=270,{ }^{\mathrm{t}} \mathrm{p}<.10,{ }^{*} \mathrm{p}<.05, * * \mathrm{p}<.01, * * * \mathrm{p}<.001$ 
Table 2

Predicting Philanthropy: Standardized and Unstandardized Estimates including Factor Loadings of Items on Entrepreneurial Orientation (EO) Construct

\begin{tabular}{|c|c|c|c|c|}
\hline & $\begin{array}{l}\text { Standardized estimate } \\
\text { (regression weight, } ß \text { ) }\end{array}$ & $\begin{array}{l}\text { Unstandardized } \\
\text { estimate }(\mathrm{B})^{\mathrm{a}}\end{array}$ & S.E. ${ }^{\mathrm{a}}$ & $p^{\mathrm{a}}$ \\
\hline \multicolumn{5}{|l|}{ Hypotheses testing $^{b}$} \\
\hline EO & .267 & .253 & .089 & .004 \\
\hline \multicolumn{5}{|l|}{ Control variables ${ }^{b}$} \\
\hline Past performance & .063 & .064 & .055 & .248 \\
\hline Access to finance & .035 & .018 & .030 & .562 \\
\hline FDI & .108 & .232 & .120 & .054 \\
\hline Export & .098 & .116 & .068 & .088 \\
\hline Size (ln employees) & .196 & .172 & .057 & .002 \\
\hline Firm age $(\ln )$ & .087 & .228 & .150 & .129 \\
\hline Retail trade & .019 & .055 & .169 & .743 \\
\hline Construction & -.005 & -.012 & .157 & .943 \\
\hline Manufacturing & -.042 & -.097 & .143 & .501 \\
\hline Wholesale & .076 & .178 & .142 & .208 \\
\hline \multicolumn{5}{|c|}{ EO factor loadings (hierarchical factor analysis) } \\
\hline EO on proactiveness & .888 & 1.368 & .182 & .001 \\
\hline EO on innovativeness & .747 & 1 & - & - \\
\hline EO on risk-taking & .600 & .870 & .134 & .001 \\
\hline $\mathrm{P} 1$ on proactiveness & .816 & .789 & .058 & .001 \\
\hline $\mathrm{P} 2$ on proactiveness & .829 & 1 & - & - \\
\hline $\mathrm{P} 3$ on proactiveness & .783 & .887 & .062 & .001 \\
\hline I1 on innovativeness & .790 & 1.127 & .117 & .001 \\
\hline I2 on innovativeness & .741 & 1 & - & - \\
\hline I3 on innovativeness & .437 & .566 & .090 & .001 \\
\hline $\mathrm{R} 1$ on risk-taking & .562 & .651 & .088 & .001 \\
\hline $\mathrm{R} 2$ on risk-taking & .561 & .682 & .092 & .001 \\
\hline $\mathrm{R} 3$ on risk-taking & .871 & 1 & - & - \\
\hline \multicolumn{5}{|c|}{ Performance factor loadings } \\
\hline Profit & .642 & .637 & .082 & .001 \\
\hline Turnover & .916 & 1 & - & - \\
\hline $\begin{array}{l}\text { Variance explained in } \\
\text { Philanthropy }\end{array}$ & \multicolumn{2}{|c|}{$25 \%$} & & \\
\hline Model fit & \multicolumn{4}{|c|}{$\begin{array}{l}\mathrm{Chi}^{2}=191.19(d f=130), \mathrm{CFI}=.95, \mathrm{TLI}=.93, \mathrm{GFI}=.94, \\
\mathrm{RMSEA}=.042\end{array}$} \\
\hline
\end{tabular}

${ }^{a}$ due to the model estimation process within the confirmatory factor analyses part of the model (bottom half of this table) one item factor loading per latent factor is fixed to 1 . SE and $\mathrm{p}$ are not estimated for those items (e.g., Kline, 2005).

${ }^{\mathrm{b}}$ All variables regressed on philanthropy as shown in lower part of Figure 2 


\section{Figure 1}

\section{Hierarchical Factor Structure Entrepreneurial Orientation}

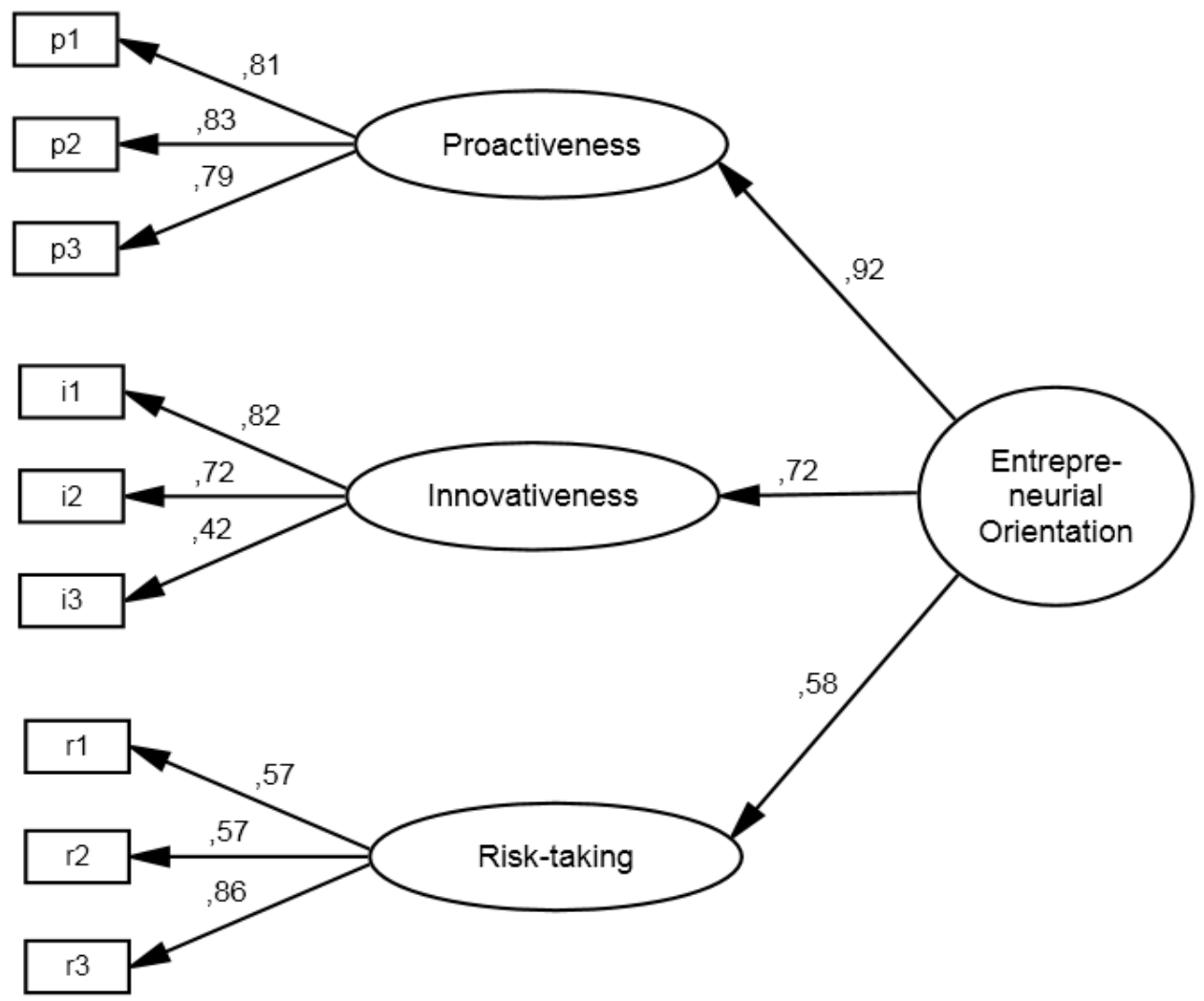

Note. All displayed coefficient estimates are statistically significant $(p<.001)$. Measurement errors and residuals are not displayed to increase readability. All figures available from the authors on request. 
Figure 2

Predictors of Philanthropy (Standardized Estimates)

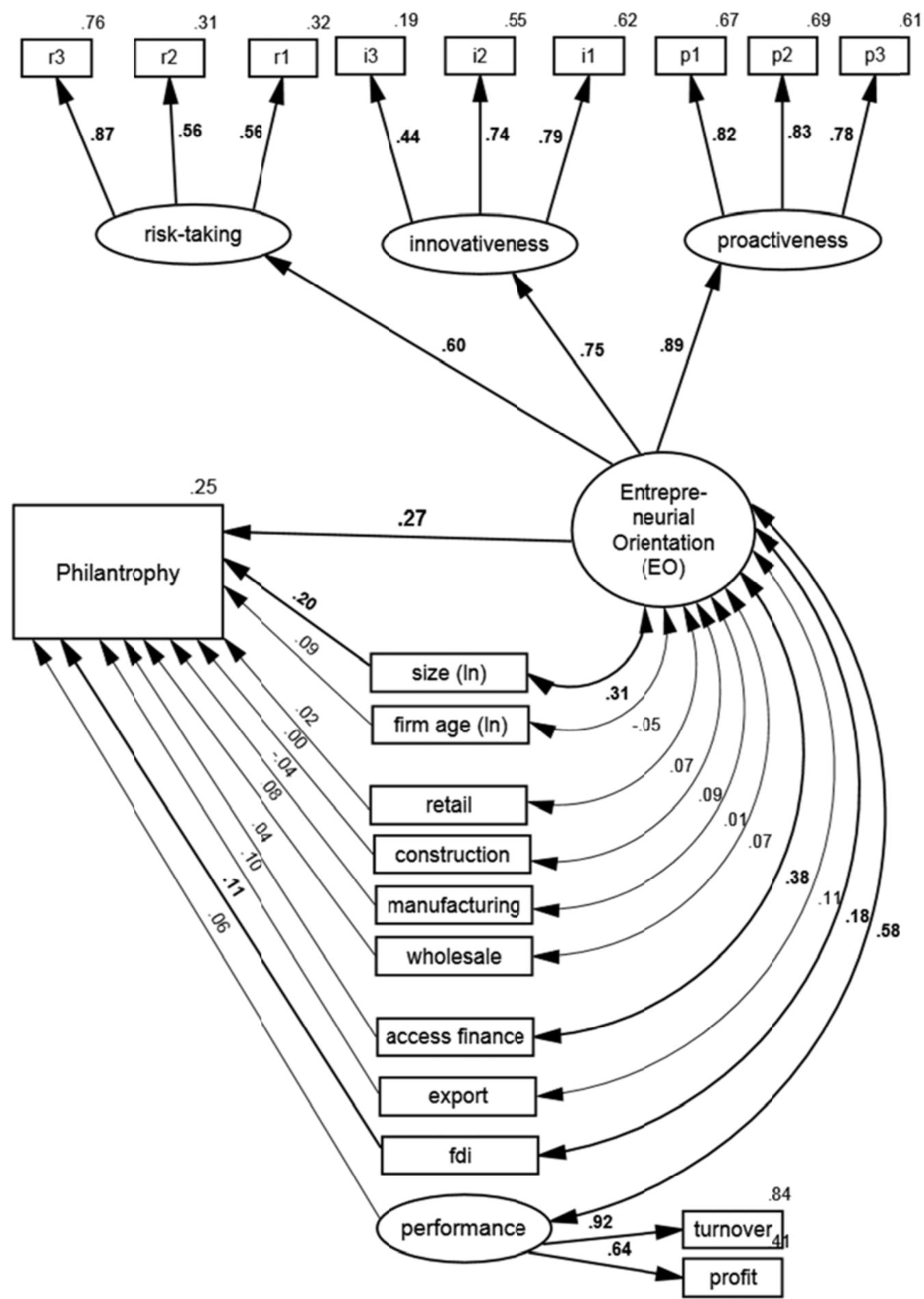

Note. Figures in bold and bolded paths are statistically significant (at least at $p<.05$ ).

Measurement errors and residuals as well as correlations amongst control variables are not displayed to preserve readability. All figures are available from the authors on request. 